\title{
Medium of Instruction, Language Proficiency and Learner Profiles: Impact of English Proficiency on the Performance of Learners following the BA Degree in Social Sciences
}

\author{
U Vidanapathirana ${ }^{1}$ and L P S Gamini ${ }^{2}$ \\ ${ }^{1}$ Department of Social Studies \\ ${ }^{2}$ Department of Management Studies
}

This paper examines how three broad groups of factors affect the capacity of learners to acquire language proficiency which in turn influence learner performance of students admitted to the BA degree programme in Social Sciences. This study programme is conducted exclusively in the medium of English; hence the need to ascertain whether the medium of instruction affects the access to all communities. In terms of access, the paper shows that the current registration pattern is highly skewed to the metropolis while learner success is found to be strongly contingent on the proficiency of the English language. Although the findings do not support sweeping generalizations concerning social exclusion they however signify the need to revisit our admission policies, regulations and support services with a view to addressing issues pertaining to access, diversity and equity of the programmes administered by the Open University of Sri Lanka.

\section{Context}

Two issues surface when decisions are taken to deliver study programmes in a second language such as English. The first issue relates to the academic merits of teaching and learning at the postsecondary levels in the second language. The second issue is the equity implications of offering programmes exclusively in the medium of English in a country where many are handicapped owing to the lack of competency in the English language. The merits and demerits of English medium education are frequently highlighted in newspapers that focus on the need for improving the language skills of university graduates in spoken and written English. The main focus of these articles is graduate unemployment. However, it is disputable whether unemployment among graduates is solely due to the lack of English language skills. When the economy does not expand at a warranted rate it is true that work opportunities become limited: these limited places are filled by those who have language plus other soft skills 
demanded by employers. This argument is known as the "demand deficiency hypothesis". Nonetheless, universities in general and the Arts faculties of our universities in particular should share part of the blame for not paying attention to the needs and nuances of the employment market (Raheem \& Gunasekera, 1996). These needs were taken into consideration by the course planners of the BA degree programme in the 1990 s.

The issue of equity and access is fundamental to Open Distance Learning (Swamy, 2002 \& Dikshit, 2002). In this context our main mandate is expanding the outreach of educational opportunities to those who are excluded owing to geographic, social, economic, cultural and language barriers (Goel, 2002). As Goel rightly pointed out:

"... the world is divided between rich and poor nations and this disparity is largely due to iniquitous access to education"

(Goel, 2002, pp. 35).

In this context, delivering study programmes exclusively in the medium of English in a country where English language training has suffered owing to years of neglect can be problematic. Currently, only those in the urban areas have access to high quality education in the English medium. To deline study programmes exclusively in the medium of English is discriminatory not only to the learners who are socially and educationally deprived but also to the language teachers from whom an unrealistically high level of competency is expected.

Therefore it may be argued that the introduction of a programme in English solely to suit "market needs" could have a high probability of undermining the entitlement of educational opportunities for the majority of prospective learners. Further, a mixture of socio-cultural, economic, political and psychological issues aggravate this situation when learners who are less proficient in English compete with others who have better English language skills. If one accepts the view that ODL has a bounden duty to increase outreach and expand educational opportunities to those segments that are deprived, then there is a need for us to examine whether there is a "language barrier" and how serious its implications are.

The designers of the BA degree programme of Social Sciences in the mid-1990s were not unaware of these issues when the decision was taken to offer this programme solely in the medium of English. This was despite strong objections by different lobbies to reverse this decision right from its inception. The arguments were weighed carefully 
using the limited information and very specific measures were taken by the Departments of Social Studies and Language Studies to mitigate the possible negative effects. The programme has been in existence for more than a decade and many batches have passed out while the intake has gradually increased. It is therefore opportune to test some of the assumptions which were made at the time of launching this programme in the mid 1990s in the light of the foregoing observations.

What were these assumptions? First, it was believed that a degree in the medium of English would have a better appeal in the eyes of the public as well as the University Grants Commission. The private sector which was consulted on the employability of graduates also held the same view. Second, it was presumed that with the substantial support offered by the Language Studies Department, these learners would be able to improve their language proficiency adequately. Third, as only a coterie of Colombo based students had opportunities to study in the medium of English, this programme would fill the void arising from the non-availability of opportunities for the underprivileged sections of Sri Lankan society. These were bona-fide expectations and assumptions. The Departments of Social Studies and Language Studies, were in fact, trying to "light" that proverbial "candle" without cursing the darkness.

It is these assumptions and expectations that we attempt to question and, if necessary, to revisit the original concept. Unfortunately, this study postulates that the third assumption is not proved correct. Many potential learners are deprived of opportunities to follow the BA programme due to their low proficiency in English. One group of learners who suffer is the learners who fail to acquire minimum marks for English at the admission test. This group belonging to the most underprivileged class was totally excluded. The second category of learners is those who managed to pass the admission test but found their language proficiency inadequate to follow the programme successfully. While some of them drop out the others failed to secure high grades to secure "good passes". In University jargon a good pass is either a first class or an upper second or a lower second in descending order.

This postulation is vindicated by the hunger for higher education among Sri Lankan youth who annually register in large numbers for external degree programmes of conventional universities. On the average more than 100,000 students register every year to pursue undergraduate studies offered by the external degree units of the 
conventional universities. These schemes have become money spinners to both Universities and to those university teachers who provide private tuition to these students. This is despite the appallingly low success rate in the external degree programmes. Another category includes those who could not enroll because the programme is effectively administered in the Colombo region only; in fact hardly any students enroll for this programme in the regional centres such as Matara. Those who enroll have also to attend day classes in Colombo which creates a considerable geographic barrier. Hence it poses the question whether this situation has produced a manifestation of a socalled 'artificial barrier' that prevents access to and success in education. To the extent that it goes against the explicit objectives of the programme this is an "artificial barrier" while its implications are considered it's real barrier.

This paper recognizes that there are other factors such as the quality of study material and instructional support, level of difficulty of examination papers and the standards of the marking schemes that have a bearing on the examination performance of those who are lessprivileged. Besides, individual, social, cultural and economic conditions also influence learner success. Thus the language issue has much wider socio-political and economic implications. However, this paper restricts its scope to those matters that are directly associated with the medium of instruction.

The paper first introduces the topic, followed by a brief discussion on methodological issues, and then deals with the primary and secondary data to explore whether the medium of English has significantly affected learner performance. In conclusion it examines the implications of the findings of this study.

\section{Literature Review}

The acquisition of second language proficiency in the context of higher education is an area that has been examined extensively (Yang et al, 2003; Collier, 1989; Vazquez et al, 1997). The scope of these inquiries includes learning difficulties and their impact on performance of second language learners. It is sometimes argued that pursuing studies in the second language creates 'barriers to learning' and eventually shrinks educational opportunities. These studies have found that the acquisition of language proficiency to pursue learning in the second language leads to mixed outcomes. These outcomes are contingent on three broad groups of factors, i.e., individual, social and institutional (Vidanapathirana \& Wickramasinghe, 2005). Although all 
three of them affect learner performance, the effects of some of them may become more crucial depending on the context in which learning programmes are conducted and on the socio-economic conditions of these learners.

The first broad group, i.e., individual factors have profound effects on learner performance. These factors include: problems of isolation (Brown, 1996); learner motivation (Chapelle, 1997); learning styles (Warschauer, 1998); and 'baseline proficiency' (Lambert, 1991). The second broad group consists of social factors which include interlearner interactions (Moor \& Kearsley, 1996), culture (Graddol, 1993) on the one hand and threatening climate that impede language acquisition on the other (Krashen, 1985). The third group deals with institutional attributes and they cover among others, technology (Johnstone \& Krauth, 1996) efficacy of student support systems, competence of teachers (Gardiner, 1997), quality of study material (Creed \& Koul, 1992), and supplementary inputs (Boyle, 1995).

The first broad group of factors, i.e., "individual" may vary in form and contribute differently to learner behaviour. For instance, the presence of a good baseline knowledge of English enhances the learner's capacity to pursue studies in the medium of English; it also facilitates the learner's capacity to seek and retrieve information and comprehend study material easily. Yet for those whose baseline proficiency is weak, learning may become a frustrating proposition. The life-cycle problems of learners also may become unbearable especially when social and institutional mechanisms are not supportive. This includes learners who are parents of infants, adult learners who are advanced in years, and those part-time learners who hold down demanding jobs.

The second group of factors include community and social support. Learners living in a close community of friends and relations receive material and emotional support to enhance their motivation. The absence of such support makes learning complex especially when academic work becomes exceptionally demanding. As studying in the second language is in itself extremely demanding the absence of emotional and material support from spouse, parents, in-laws, coworkers and superiors adversely affect learner motivation. Learners are often subjected to humiliating treatment by peers whose language proficiency is superior or teachers who deliberately neglect weak learners.

The third group of factors involves the status of institutional support mechanisms. The physical and social distance to the institution, 
quality of study material, quality of day classes, nature of feedback received by the students and also the ambience of the support services, fall into this category. It is argued that students face their "moment of truth" when they enter the regional centre seeking various services. At the OUSL, student support services are minimal. Support services staff are more often than not discourteous and their responses to genuine queries and clarifications are off hand and insolent. Not only does it create a poor impression of the University but also discourages learners who are already affected by other learning difficulties. Additionally as the quality of study material is poor and the day classes are badly conducted, this situation is aggravated. This is a sad truth and hence language is not the only issue that learners find difficult to cope with (Ranasingha et al 2007).

\section{The Objectives of the paper}

The objectives of this paper are as follows;

- to examine whether the level of English language proficiency has radically influenced the performance of learners following the BA degree programme. This influence should be evident on admission to the programme (access to), their successful completion (success of);

- to evaluate the quality of their learning outcomes which are measured in a continuum from failure at one extreme to a pass with a distinction at the other;

- to examine whether the impact of English Language proficiency is more significant in certain subject disciplines than others and

- to ascertain whether the BA degree programme is tilted towards a selected segment of the potential learner population, favouring those affluent learners who live in the Western province of the country.

\section{Hypotheses}

This paper attempts to test three hypotheses. Stated in null form the first hypothesis affirms that 'examination performance of learners will be the same irrespective of their English language proficiency'.

Alternatively higher the English Language marks of learners, the better are their overall examination performance.

The second hypothesis in null form states that level of English language proficiency affects all three subject disciplines of the BA 
degree programme, i.e., Sociology, Economics and Mass

Communication. Alternative hypothesis states that some subject disciplines require higher language proficiency than others.

The third hypothesis in null form states that enrolment of learners following this programme is not skewed towards an "exclusive group". The concept of "exclusive group" infers that the programme has an elitist bias in terms of enrolment and success. If this is true, the OUSL has failed in its equity and outreach expectations. The alternative hypothesis states that learner enrolment is skewed towards an "exclusive group".

\section{Conceptual framework and methodological issues}

This study presumes that the three groups of factors, i.e. individual, social and institutional affect the motivation of learners to pursue their studies. This is over and above the "cognitive" problems that are inherent in specific disciplines such as mathematics or economics. In fact it is the presence or absence of the same group of factors that either frustrate or reinforce learner motivation. Table 1 below outlines the direction of causation of these three groups of factors.

It is postulated that the cumulative effects of all these three broad groups of factors frustrate and/or stimulate learner performance depending on the way they are presented. The language issue has an overriding influence on all three broad groups of factors. This is because of the sense of elitism that goes with language proficiency; those who have English proficiency are relatively more self-confident and hence assertive while those who lack English proficiency are reticent and more uncommunicative.

Table 1- Group of factors affecting learner performance and the direction of influence

\begin{tabular}{|l|l|l|}
\hline $\begin{array}{l}\text { Broad group of } \\
\text { factors }\end{array}$ & $\begin{array}{l}\text { Enhances the learning } \\
\text { process }\end{array}$ & Frustrates the learning process \\
\hline Individual & $\begin{array}{l}\text { E.g. Baseline proficiency of } \\
\text { English }\end{array}$ & $\begin{array}{l}\text { Lack of baseline proficiency of } \\
\text { English }\end{array}$ \\
\hline $\begin{array}{l}\text { Community and } \\
\text { social }\end{array}$ & E.g. Family status and support & $\begin{array}{l}\text { Poor family status and lack of } \\
\text { support }\end{array}$ \\
\hline Institutional & $\begin{array}{l}\text { E.g. Physical and social } \\
\text { distance to the centre }\end{array}$ & $\begin{array}{l}\text { Longer physical and social distance } \\
\text { hindering use of the support } \\
\text { services }\end{array}$ \\
\hline
\end{tabular}




\section{Methodology}

The schematic framework given in Table 1 demonstrates the direction of causation with respect to individual, social and institutional factors governing learner performance. Accordingly the presence or absence of different factors generate different learning outcomes. For instance, a high level of proficiency in the English language influences learner performance significantly while its absence aggravates the condition of "exclusion". To test these relationships we use a combination of primary and secondary data. These include questionnaire surveys, focus group discussions and the extraction of secondary data from the official records maintained by the OUSL.

The questionnaire survey covered 260 learners who sat for the final examination held in September 2008; only 126 (48 \%t) of the responses were in usable form. This was supplemented by a series of ten (10) Focus Group Discussions (FGD) with a group of 67 learners who volunteered to share their learning experiences with the principal researcher. The study also investigated documentary evidence such as examination results and records maintained by the Student Affairs Division of the University (182 examination records, 336 student registration files, 126 questionnaires and 6 FGDs covering 67 learners).

The questionnaire gathered information on learner profiles, learning methods and problems, student support services and assessment of learners regarding the quality of inputs provided by the University. The FGD were especially effective in garnering information on the userfriendliness of the study material, teaching quality, feedback mechanisms and learner perceptions on the use of the English medium.

Secondary data provided some baseline information on learner performance. This consisted of records maintained by the Examinations Department of the University on 182 learners whose marks had been submitted for the scrutiny of the Board of Examiners. It compared the Average Mark Levels (AML) for courses LSE 2303 and LSE 3303 with the Weighted Average Marks (WAM) of learners for compulsory courses. The AMLs covered marks for English proficiency while WAMs covered marks for three compulsory courses in Levels Three (III), Four (IV) and Five (V) for the subject disciplines of Economics, Mass Communication and Sociology. This paper uses regression analysis and analysis of variance to ascertain the impact of English language proficiency on the overall performance as well as performance by disciplines. For this purpose the marks scored at the 
final evaluation for English were grouped into three categories, i.e.., one $(<40 \%)$, two (41-60\%) and three (> 60\%).

To ascertain whether the BA degree programme was "inclusive" in terms of geographic, economic, social and class parameters, the Univariate Chi-square analysis was used. The concept of "inclusiveness" is one of the fundamental aspects of development: it seeks equity in opportunities to participate in all activities including education, health, employment and income generation. Four specific sub-hypotheses were used to test the aspect of "inclusiveness". They are the distance to the CRC, types of newspapers frequently read by the learners, having a private study facility at home and the last school attended by the learner.

\section{Testing of the three Hypotheses}

The WAM was compared with AML which showed that the higher the average marks for English language the better the performance in terms of WAM at the final examination(s). This seems to indicate that the level of English language proficiency directly influences the quality of leaner performance. In fact, the FGD data revealed that learners with better English language proficiency scores tend to secure better passes. This was the perception of the coordinators of the programme as well.

Table 2 summarizes WAM scores by three categories of learners where those who obtained less than 40 per cent for English Language tests have the lowest WAM score for final examination (39.63). Conversely, learners with more than 60 per cent for English language papers have the highest WAM score of 52.12. The students whose marks for the English language paper ranges from 41-60 per cent have WAM of 45.81. These differences show that WAM for subject disciplines vary depending on AML scores of learners. Therefore it was necessary to test whether these differences are statistically significant for which the ANOVA test was conducted.

The hypothesis on this relationship in form states that examination performance of learner does not differ significantly irrespective of the level of their English language proficiency. The One-way Analysis of Variance (ANOVA) results indicate that this hypothesis does not hold correct at 99 per cent confidence interval, $F(2,178)=13.37, p<.001$. The rejection of the hypothesis in null form confirms that English language proficiency has a direct bearing on learner performance in the BA Degree programme in Social Sciences. 
Table 2 - ANOVA results of WAM by three categories of English proficiency

\begin{tabular}{|l|l|l|l|l|}
\hline Indicator & $\begin{array}{l}\text { Category 1 } \\
\text { English Marks } \\
\mathbf{4 0}\end{array}$ & $\begin{array}{l}\text { Category 2 } \\
\text { English Marks } \\
\mathbf{4 0 - 6 0}\end{array}$ & $\begin{array}{l}\text { Category 3 } \\
\text { English Marks } \\
>\mathbf{6}\end{array}$ & F- value \\
\hline $\begin{array}{l}\text { WAM (Weighted } \\
\text { Average Marks) }\end{array}$ & $39.63 \mathrm{a}^{*}, \mathrm{~b}^{* *}$ & $45.81 \mathrm{a}^{*}, \mathrm{c}^{* *}$ & $52.12 \mathrm{~b}^{* *}, \mathrm{c}^{* *}$ & $13.37^{* *}$ \\
\hline
\end{tabular}

Notes -1- Turkey's post-hoc test was used for inter-group comparison;

2 - a $=$ category 1 different form category 2 ,

$\mathrm{b}=$ category 1 different from category 3 ,

$\mathrm{c}=$ category 2 different form category 3 .

3- Significance level; ${ }^{*} \mathrm{P}<0.05$; and ${ }^{* *} \mathrm{P}<0.01$

This result was supported by the coefficient of correlation obtained for English language marks (AML) and final examination scores (WAM).

The results show that exam performance is positively related to the marks for English language, with a coefficient of $r=0.51$ which is also significant at $\mathrm{p}<0.0001$. The $\mathrm{R} 2$ of 26.1 per cent confirms this association in which this single variable of English language proficiency being responsible for learner performance. Accordingly about 26 per cent of the total variation is determined by the single factor of language proficiency. This is a sizable contribution as whatever the other factors listed under the three broad categories are responsible for the remaining 74 per cent of the pattern of variation.

The study also examined whether the differences stated above are significant. To ascertain this Turkey's post-hoc test was applied. It showed that mean scores of category 1 (English mark < $40 \%$ ) which recorded the lowest average examination scores is significantly different from the mean scores of category 2 (English language marks $40-60 \%$ ) at .01 level of significance (mean difference 6.18, $\mathrm{p}=0.0001$ ). Secondly, the mean difference (12.49) between category 1 and category 2 was significant at 1 per cent level with $\mathrm{p}$-value $=.003$. Thirdly, the mean difference (6.30) between category 2 and category 3 is significant at 1 per cent level with $\mathrm{p}=.003$.

The second hypothesis examined whether the three subject disciplines require different levels of English proficiency. To test whether the influence of the proficiency of English language occupies a more significant position for certain subject disciplines than the others, AML was compared with the performance of those who obtained more than 50 marks for Economics, Sociology and Mass Communication. 
Table 3 - AML by disciplines of Economics, Sociology and Mass Communication

\begin{tabular}{|l|l|c|}
\hline Course & English Mean Score & Standard Deviation \\
\hline Sociology & 60.38 & 8.91 \\
\hline Economics & 55.84 & 11.64 \\
\hline Mass Communication & 55.73 & 10.37 \\
\hline
\end{tabular}

Note: $\mathrm{F}=2.89, \mathrm{p}<0.058$

Table 3 shows that there exists a variation in the AMLs pertaining to these three courses. For instance, the high achievers in Sociology (obtaining more than 50 marks) exhibited high levels of proficiency in English (60.38). It is presumed that Sociology in particular requires higher English proficiency (60.38) to achieve better marks while Economics requires a relatively low English score of 55.84 marks. This is plausible because Sociology by nature involves explanations using complex sentence structures while Economics involves the use of tables, charts, mathematical and geometric sketches to explain complex phenomena.

To establish whether this variation is statistically significant the ANOVA test was used. The ANOVA results indicate that there is no statistical evidence to reject the null hypothesis that influence of English language proficiency is felt equally on all three subject disciplines' $(F=2.89, p<0.058)$. In other words, the finding that sociology requires higher English proficiency as given in Table 2 is not proved statistically significant at 0.05 level. Accordingly, irrespective of the subject discipline chosen, all three of them require comparable language proficiency to pursue this programme.

The third hypothesis was tested using four attributes that characterize the exclusive (elitist) nature of learner enrolment in particular and performance in general. Each of these attributes is presented as four sub-hypotheses. The concept of social exclusion deals with the absence of a certain group of people which is depicted by not having mechanisms to include all sections of the population in the development process. Therefore efforts should be taken to make programmes and activities inclusive. Its absence leads to social exclusion and inequity. They are used to examine whether the learners following the BA degree programme belong to an "exclusive club" (elitist) rather than being the inclusive group as envisaged in the original plan of this programme. The "typical learner" is an indispensable concept used for programme planning in ODL. As for the 
BA degree programme the OUSL aims to reach out to those learners who are scattered in various parts of the country who are deprived of opportunities to study in the English medium.

Before embarking on statistical testing of the third hypothesis it is important to typify the learner profile of the BA degree programme. The following sections sum up the major aspects of their profile. On the whole the learner population is mostly employed (76\%) and most are females (60\%). Of those who are employed 63 per cent are holding managerial positions at different levels while another 30 per cent are teachers. About 47 per cent of the learners are married while the mean age of the learners is 33 years and 10 months with a standard deviation of 10.8. Thus many of these learners are employed, married and relatively mature in terms of age and experience; therefore they are not young, school-dropouts. This needs to be compared with the learner profile of the BSc Degree programme where the mean age is 25 while those in employment is 48 per cent (Jayatilleke, 2002; pp. 139). These attributes of typical learners also contribute to enhancing learning outcomes of the BA Social Science students.

Nonetheless, there are many other attributes that show signs of inequity. An important attribute of these learners is their skewed regional distribution. This issue covers two major dimensions. The first dimension is whether the programme of Social Sciences has a wider outreach in terms of regional distribution. If so these learners should represent all the regional centres of the OUSL. On the contrary, our findings showed that about 97.5 per cent of learners are registered at the CRC. The OUSL has 6 regional centres, i.e., Colombo, Matara, Kandy, Jaffna, Batticaloa, and Anuradhapura. The examination was conducted in Colombo, Kandy and Matara. Having 97.5 per cent concentration at the CRC however is appallingly inequitable.

It is this aspect of regional distribution that led us to select the physical distance from the learner's residence to the CRC to test whether the learners are clustered in the Colombo metropolitan area. If so, it signifies the extent of geographic exclusion in terms of learner enrolment. This query resulted in two vital pieces of statistics. Firstly, eight miles is the model value of the distance from the learner's residence to the CRC. Secondly, about 56 per cent of the learners who responded are resident within the $20 \mathrm{~km}$ radius while another 20 per cent are resident within $20-49 \mathrm{~km}$ radius. This in other words shows that a forceful 76 per cent of the learners reside within the $50 \mathrm{~km}$ radius of the $\mathrm{CRC}$. 
This means the programme is highly centralized for learners in the Western province of Sri Lanka. The first attribute used to test the third hypotheses therefore was whether the learners are heavily clustered in the Colombo district as denoted by the distance to the CRC. If that is so it undermines the equity and access principles of distance education. Only 24 per cent of learners live further than the $50 \mathrm{~km}$ radius.

Thus the first sub-hypothesis states that a significantly large share of learners following the BA degree programme live within the $20 \mathrm{~km}$ radius. The $\mathrm{X} 2$ value for this distribution is 6.635 and it is significant at 1 per cent level. It shows that the current pattern of student admissions undermines one of the fundamental principles of distance education, i.e., removal of geographic distance.

The second attribute selected to test equity and access is the last school attended by the learners. Schools in Sri Lanka are classified according to three categories, i.e., schools below $\mathrm{C}$ category, $\mathrm{AB} 1$ and national schools and prestigious schools. Schools below $\mathrm{C}$ category offer up to GCE (O/L) only in the Arts stream while AB1 and National schools offer educational opportunities up to GCE (A/L) sometimes in all three streams: Arts, Science and Commerce. Some of the schools in this category lack the facilities needed to teach Science, Mathematics and English language effectively. Prestigious schools located in the main cities of Colombo, Kandy Galle etc. are fully equipped with Science and English language teaching infrastructure. Examples of schools in this category are: Ananda College, Ladies College, Trinity College, and Richmond College. In this context, the share of learners following the BA in Social Sciences from "C" schools is less than 12 per cent. This reveals that the BA degree in Social Sciences seems to reach out more extensively to learners from more advantaged schools. Therefore the second sub-hypothesis to test the incidence of "exclusion" is that the distribution of learners whose last school attended is significantly skewed towards more advantaged schools. The $\mathrm{X} 2$ value pertaining to this distribution is 24.19 . It is significant at 1 per cent level. 


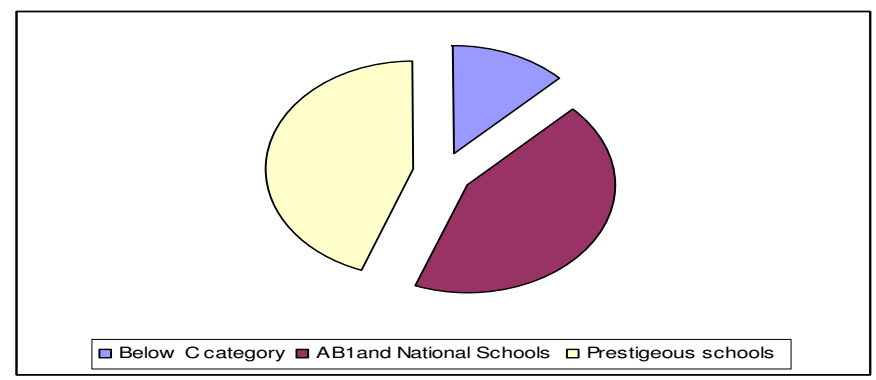

Figure 1 - Schools attended by the learners Source: Survey data

It means that the OUSL has unwittingly promoted a system that supported social exclusion. In this context the medium of instruction appears to be one of the most potent factors that contributed to this predicament. This study on the BA degree programme is only the small perceptible part of a much larger problem. It is difficult to perceive whether other degree programmes have also been confronted by this problem. The failure to introduce corrective measures such as providing additional support to weak learners and to expand the outreach of the study programme has also exacerbated this situation.

The third attribute selected is to examine the number of learners having private study facilities in their own homes. Educationally, this looks very desirable. However, given the extent of the housing congestion in the country, only those households belonging to the topmost income quintiles can afford this facility. According to Figure 2 about 60 per cent of the respondents reported that they have separate study facilities. This once again underlines the fact that these learners in the BA degree programme belong to a more privileged strata of the Society.

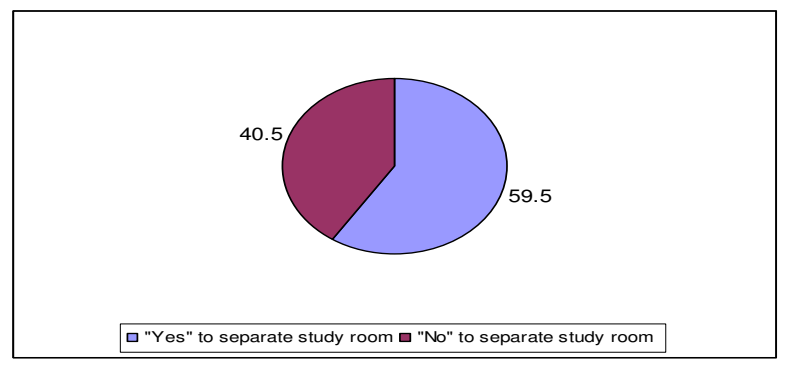

Figure 2: Share of learners having a separate study room at home Source: Survey data 
The third sub-hypothesis examines whether there is a significant difference between those learners having separate study rooms to carry out their educational activities to those who do not have such a facility. Central Bank data for 2003/04 states that housing congestion in general has eased during the past two decades although much of this reduction was due to the increase of housing stock among the middle and high income earners (Central Bank, 2005). It was revealed that about 60 per cent of learners enjoy separate study facilities at home. The X2 value of this distribution was 5.165 and it was significant at 5 per cent level.

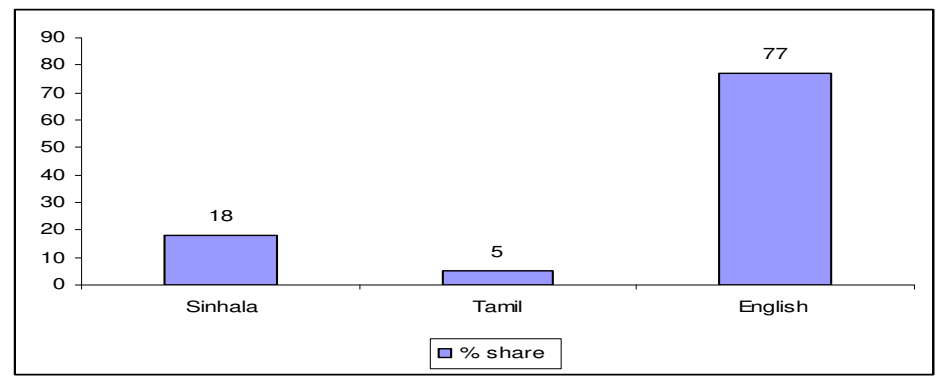

Figure 3: Medium of newspapers read by the learners in percentages Source: Survey data

The final sub-hypothesis covers the use of print medium for news and information. Responding to the question on the most popular newspaper, a separate table was constructed by re-grouping learners' responses by the language i.e. Sinhala, Tamil and English of the publication. It was revealed that about 77 per cent of these learners read "English dailies". Although newspaper readership is high in Sri Lanka the number of those who read English newspapers is restricted. This attribute is important because it typifies the possible bias in the admission policy of the OUSL. The information given above was examined using the Chi-square test. It yielded an X2 value of 86.66 which also is significant at 1 per cent level.

These attributes corroborate the argument that the learner community of this programme is skewed to the relatively "well-to-do" income quintiles. In Sri Lanka about 68 per cent of learners who sit for GCE $(\mathrm{O} / \mathrm{L})$ examination fail in the English paper. However, GCE O/L results of these learners show that more than 82 per cent of them have earned grades above $C$ pass and 38 per cent have earned an " $A$ " pass. The FGD outcomes have shown that these learners use the Internet frequently to obtain information for their level four and level five 
subjects. The internet access and usage in Sri Lanka still remains low at around 5 per cent (Central Bank, 2005).

The higher level of English proficiency among the majority of these learners has given rise to socially unacceptable outcomes. For example, "bullying" by those who are proficient in English appears to have been evident in some classes. This affects the self-respect of learners who lack proficiency in spoken English. Table 5 confirms that such learners are exposed to humiliation during their face to face contact sessions with peers.

Table 5: Stigmatizing learners with weak language skills

\begin{tabular}{|l|l|l|l|l|}
\hline Statement / perception & $\begin{array}{l}\text { Strongly } \\
\text { agree }\end{array}$ & Agree & $\begin{array}{l}\text { No } \\
\text { response }\end{array}$ & Disagree \\
\hline $\begin{array}{l}\text { Do learners who are proficient in English } \\
\text { humiliate you when you try to interact with } \\
\text { them }\end{array}$ & $8(6.3)$ & $\begin{array}{l}28.6 \\
(32.4)\end{array}$ & $15(12)$ & $67(53)$ \\
\hline $\begin{array}{l}\text { Teachers sometimes ignore me when I try } \\
\text { to interact with them because of my lack of } \\
\text { English language proficiency }\end{array}$ & $1(0.8)$ & $24(19)$ & $17(13.5)$ & $84(66.7)$ \\
\hline $\begin{array}{l}\text { Co-workers tease me for trying to learn in } \\
\text { the English medium }\end{array}$ & $1(0.8)$ & $36(29)$ & $28(22)$ & $61(48)$ \\
\hline $\begin{array}{l}\text { Even my grades / marks are low merely } \\
\text { because of my low level of English language } \\
\text { proficiency. }\end{array}$ & $1(0.8)$ & $18(14)$ & $20(16)$ & $80(64)$ \\
\hline
\end{tabular}

Source: Survey data

An overwhelming number of learners with good English language skills have rejected the notion that they knowingly humiliate learners who are not proficient in English. This is possible in a situation where many of them are at an advantage. However, for the victims the perception of humiliation is stigmatizing. It makes learning in the second language all the more difficult.

Statement one in Table 5 illustrates that there is a problem of perceived exclusion and discrimination. This is undesirable as it could lead to other manifestations such as weak learners becoming suspicious of favouritism by staff members even when it is not really present. Statement two can be an outcome of "perceived discrimination" by learners rather than real discrimination by teachers. However, this needs further investigation. 


\section{Discussion of findings and concluding remarks}

This study has highlighted three important aspects of ODL that are exceedingly useful for the policy makers and planners of ODL. Firstly, the decision to initiate the BA degree programme in the medium of English is not intrinsically inappropriate. Where the OUSL has failed is that it did not establish mechanisms to admit weak learners and provide the necessary supplementary assistance to help them continue their education. Secondly, the teachers / coordinators should have provided additional face to face sessions for those who found it difficult not only to comprehend the study material but also to tackle assignments. Thirdly, the OUSL also needs to ensure that its regional network is fully operational in terms of programme delivery. The concentration of activities in the central campus in Colombo goes against the very concept of ODL. Many of the activities currently controlled by the central campus should therefore be decentralized so that learners from the periphery too would be able to benefit from ODL.

Finally a word of caution is also warranted at this stage because two methodological problems may have affected the validity of the findings of this study. The first problem was our dependence on those learners who have been continuing with the programme for primary data. Given the skewed distribution that indicates that the majority of learners are urbanized / privileged it seems relevant to point out that the answers given by them would be skewed. The second problem was our inability to collect information on those learners who had already dropped out. These factors should be taken into account when interpreting the findings and conclusions of this study.

The twentieth century was said to be a century of inequity. This divide is the greatest challenge before us. Our failure to address it effectively and speedily will threaten social harmony and political stability. The findings of this paper show that there is a direct and significant association between proficiency in the English language and learner performance. It confirms our postulation that the level of English proficiency influences the level of success of these learners; it also confirms that the level of proficiency in English generates social differentiation. The BA degree programme has translated this advantage into a mechanism that widens the divide. This does not mean that the OUSL should throw the BA degree ("the baby") out with the bathwater". On the contrary, the Departments of Social Studies and Language Studies should evolve mechanisms to preserve and 
nurture the baby. The OUSL's inability to do so will undermine the concepts of equity in terms of access for and success in ODL.

\section{References}

Boyle, R. (1995). "Language teaching at a distance: From the first generation model to the third", System, 23, 1, 283-294.

Brown, K. M. (1996). "The role of internal and external factors in the discontinuation of off-campus students". Distance Education, $17,1,44-71$.

Central Bank of Sri Lanka (2005). Consumer Finances and Socio economic Survey, 2003/04, Part 1, Colombo: Central Bank of Sri Lanka.

Chapelle, C. (1997). "CALL in the year 2000: Still in search of research paradigms?”. Learning and technology, 1, 1, 19-43.

Collier V. (1989). 'How long: A synthesis of research on academic achievement in a second language', TESOL Quarterly, 23, 509-531.

Creed, C. \& Koul, B. (1993). "Language issues in English medium, tertiary level DE courses for ESL learners", Language Issues in Distance Education (p. 48-52), England, United Kingdom: Dunford Seminar Report. ERIC Document No: ED370 406.

Dikshit, H. P.; Garg, S.; Panda, S. \& Vijayshri (eds) Access and Equity: challenges for open and distance learning, Kogan Page: New Delhi, India.

Gardiner, L. F. (1997) "Producing dramatic increases in student learning: can we do it?" National teaching and learning Forum, 6, 3, 58-71.

Goel, V. (2002), "Access, quality, and equity through diversity: commonwealth perspective". In H. P. Dikshit, S. Garg, S. Panda, \& Vijayshri (eds) Access and Equity, Kogan Page: New Delhi, India.

Graddol, D. (1993). "Language Issues in Distance Education at tertiary level: Language Issues in Distance Education, (pp. 23-25), Dunford Seminar Report; England, United Kingdom.

Jayatilleke, B. G. (2002), "Asian Students: Are they really different". In H. P. Dikshit, S. Garg, S. Panda, \& Vijayshri (eds) Access and Equity: challenges for open and distance learning, Kogan Page: New Delhi, India. 
Johnstone, S. M. \& Krauth, B. (1996). "Balancing quality and access: some principles of good practice for the virtual university", Change, $28,2,38-41$.

Krashen, S. (1985). The Input Hypothesis, Beverly Hills, CA: Laredo Publishing Company.

Lambert, R.D. (1991). Distance education and foreign languages. Washington DC. John Hopkins University, National Foreign Language Centre, ERIC Document No. ED. 334-833.

Moore, M. \& Kearsley, G. (1996). Distance Education: A systems view. Belmont, CA: Wadsworth Publishing Company.

Raheem, R. \& Gunesekara M. (1994) "English and Employment in the private sector of Sri Lanka" Sri Lankan Journal of Educational Research, 4, 1, 1-16.

Swamy, V. C. K. (2002) "Open distance learning, and concerns of access and equity”. In H. P. Dikshit, S. Garg, S. Panda, \& Vijayshri (eds) Access and Equity, Kogan Page: New Delhi.

Vazquez, E. G, Vazquez, L. A.; Lopez, I. C. \& Ward, W (1997). "Language Proficiency and Academic Success: Relationships between Proficiency in two languages and Achievement among Mexican American Students". Bilingual Research Journal, 21, 4, 336-352.

Vidanapathirana, U. \& Wickramasinghe, T. (2005). "Making sense of the Language Barrier; The Case of BA Social Science Students Recruited under the Relaxed Scheme of Admission in 2003". In Proceedings of the OUSL Silver Jubilee Academic Sessions, November 24-25, 2005, Open University of Sri Lanka, Colombo (160-165).

Warschauer, M. (1998). "Interaction, negotiation and computer-mediated learning". In M. Clay (Ed.), Practical applications of educational technology in language learning, Lyon, France: National Institute of Applied Sciences.

Yang, C. H. \& Meyen E. L. (2003). "Barriers to Implementing Large-scale Online Staff Development Programs for Teachers", Online Journal of Distance Learning Administration, 6, 4, http://www.westga.edu/ distance/ojdla/winter64/meyen64.htm 